agencies. All this is put forward as a new "rationale of budget making". The trouble is that it is not a rationale but the opposite-an attempt to avoid thinking hard about individual proposals for research.

The most immediate difficulty is that of making a meaningful distinction between largely academic research sponsored by the National Science Foundation and the long-term work which agencies such as the Navy Department are encouraged to support in the belief that it will ultimately bring practical advantages. Thus the U.S. Navy is just as likely as a university research unit to decide that a long-term study of the movement of ocean currents would be worthwhile. This, indeed, is why the U.S. Navy has such a splendid record in supporting long-term research. Presumably there was once a committee paper setting out just how the navy would in the long run benefit from the successful studies of X-ray emission from the Sun which have been sponsored by the Office of Naval Research.

There is a real danger that the artificial distinction of the kind now proposed would turn out to be cramping either for the mission-oriented agencies or for the National Science Foundation. It is even more unrealistic, however, to suppose there can ever be a predetermined ratio of the cost of long-term and shortterm research supported by one agency. 'This is bound to be an exceedingly arbitrary business and open to abuse as well. What the committee should have asked itself is how arrangements should be made to see that long-term research programmes and grant-giving are properly co-ordinated, and what arrangements there should be for stabilizing the scale of financing for longterm work against the fluctuations of enthusiasm for short-term goals. It would be an important step in this direction if the National Science Foundation were given a greater share of the money for oceanography. The councils created by the White House in July last year should help with co-ordination. But simple rules of thumb will create more problems than they solve.

\section{MARKING TIME AT GENEVA}

$I_{T}$ is entirely welcome that the nuclear powers have decided to wait for further discussions before tabling their draft treaty on the non-proliferation of nuclear weapons at the United Nations Disarmament Committee at Geneva. Three weeks ago (see Nature, 213, $641)$ the nuclear powers seemed unreasonably optimistic about the chances of a quick agreement. Events have clearly taught them a little caution-and have set in train a flurry of diplomatic activity. Sir Solly Zuckerman has been in Bonn, doing his best to allay German anxieties about the Treaty. Lord Chalfont, the minister of state responsible for disarmament at the Foreign Office, has been trying to do the same in Brussels, where Euratom is at once offended and threatened by the suggestion that some other agency - the International Atomic Energy Agency at Vienna- should assume international responsibility for safeguards and inspection. Other nuclear powers are engaged on the difficult discussions with India about the kinds of political guarantees which would at once be practicable and feasible. This is one reason why there was a welcome for the announcement a week ago that the United States and the Soviet Union have agreed to hold discussions on measures to limit their own deployment of strategic weapons. A tacit agreement between two similarly placed powers is much more easily arrived at than an agreement affecting everybody.

That, however, is no reason for giving up hope of what will happen at Geneva. The first need is to create a sense of realism there. It seems now to be acknowledged that a treaty to prevent the spread of nuclear weapons must be backed up by the most rigorous forms of international inspection, and the United Nations Assembly made it plain last year that the IAEA should be the instrument of choice. But the agency is only now beginning to stretch its wings. Although there are now more than fifty reactors on the books of the agency's inspectors, only a handful of these are power reactors. So far, they only cover one plutonium separation plant, and rules to cover diffusion plants, fabrication plants and uranium mines are not yet in operation. Nobody is to blame for this, but it is bound to be several years before comprehensive arrangements are worked out. That time scale must be reckoned with by the nations at Geneva. If they are lucky and get a quick agreement, they may have to put up with a provisional safeguards system. The delay will only be an insuperable obstacle if they do not know it in advance.

The political problems at Geneva are just as daunting, although it is pleasing that much less is now heard of the loss of the alleged uncovenanted benefits which could be expected to flow from a military programme of nuclear development. This view, of course, is nonsense. The argument about commercial secrecy, much heard in West Germany, will have less force when it is more widely recognized that research and development facilities would be less open to inspection than power plants. The argument about the place of Euratom in a system of international safeguards is less tangible, but in the long run it is unthinkable that the international agency should delegate its responsibilities for inspection to what is essentially a private organization. (That said, the existence of Euratom controls could make the task of international inspection lighter.) But the real difficulty about the treaty is its asymmetry. Whatever language may be used, the draft as it stands must seem to the non-nuclear powers to be a means of perpetuating the nuclear status of the others. Until the nuclear powers find some way of modifying this impression, they are not likely to get a treaty. Their insistence on rigorous inspection will only make if easier for the non-nuclear powers to retort by asking for a cut-off of production. On the face of things, the nuclear powers will be hard pressed to give a convincing reason why this should not be combined with the provisions on non-proliferation. 